\title{
KAJIAN PENGELOLAAN TATA AIR DAN PRODUKTIVITAS SAWIT DI LAHAN GAMBUT \\ (Studi Kasus : Lahan Gambut Perkebunan Sawit PT Jalin Vaneo di Kabupaten Kayong Utara, Provinsi Kalimantan Barat)
}

\author{
A Study of Water Management and Palm Oil Productivity in Peatlands \\ (Case Study : Peatlands of PT Jalin Vaneo's Palm Plantation in North \\ Kayong District, West Kalimantan Province)
}

\author{
Hasmana Soewandita ${ }^{1 *}$ \\ 1) Pusat Teknologi Reduksi Risiko Bencana - Badan Pengkajian dan Penerapan Teknologi, Gedung \\ GEOSTECH (820), Kawasan PUSPIPTEK, Serpong, Tangerang Selatan \\ *E-mail : hsoewandita@gmail.com
}

\begin{abstract}
Intisari
Pengembangan lahan gambut untuk perkebunan kelapa sawit sudah demikian pesatnya akibat terbatasnya lahan mineral yang tersedia dalam hamparan yang luas. Tidak sedikit pemahaman akan karakteristik lahan gambut untuk pengembangan kebun kelapa sawit juga sangat terbatas baik aspek ekologi maupun agronomi dan tanah. Tujuan dari kajian ini adalah untuk mengkaji sistem tata air pada lahan gambut dalam kaitannya dengan karakteristik lahan baik aspek biofisik maupun lingkungan. Hasil kajian menunjukkan bahwa saluran reklamasi baik pada saluran utama maupun pada saluran blok banyak terjadi overdrainage dan hal ini sangat rentan terhadap bahaya kebakaran lahan gambut. Pemahaman karakteristik lahan gambut yang kurang memadai serta pengelolaan ketinggian muka air saluran yang kondisinya dibawah kedalaman lapisan pirit mengakibatkan terbentuknya oksidasi pirit. Saluran yang terindikasi terjadi oksidasi pirit terjadi pada saluran blok lahan pertanaman berimplikasi terbentuknya racun (jarosit), sehingga hal ini sangat berbahaya bagi pertumbuhan tanaman dan produksi kelapa sawit. Pirit yang teroksidasi ini mempunyai $\mathrm{pH}$ yang sangat masam sehingga kelaruran logam seperti Al sangat tinggi dan berdampak pada keracunan bagi tanaman. Pengendalian muka air diatas lapisan pirit, flushing dengan fresh water dan pengapuran merupakan solusi dalam penangan oksidasi pirit, sehingga produktivitas sawit bisa berkelanjutan.
\end{abstract}

Kata Kunci : Lahan Gambut, Pirit, Tata Air, Produktivitas.

\begin{abstract}
Peatlands development for the purpose of oil palm plantations has been very rapid recently due to limited availability of dry lands in the vast expanse. In addition, the understanding of peatlands characteristics for oil palm plantation development is also very limited from an ecological, agronomical? and soil perspective. The purpose of this study is to assess water system on peatland with respect to the biophysical and environmental aspects of soil characteristics. The results showed that there is an existence of a large overdrainage on both the main and the channel block of the reclamation channels, which is very vulnerable to peat fires. Inadequate understanding of peatland characteristics, together with water level management of a channel which lies on a depth below that of a pyrite layer, would both combine to form pyrite oxidation. The channel which is contaminated with pyrite oxidation lies on the channel block that is intended for croplands. This implies that a toxic substance, jarosite, will then be formed that will endanger plant growth and oil palm production. The oxidized pyrite has a very acidic $\mathrm{pH}$ such that it will dramatically increase the solubility of metals such as Al and would also impart toxicity to plants. Control of the water level above the pyrite layer, fresh water flushing and liming are existing solutions in handling pirit oxidation, so as to make palm productivity sustainable.
\end{abstract}

Keywords : Peatlands, Pyrite, Water Management, Productivity. 


\section{PENDAHULUAN}

\subsection{Latar Belakang}

Sebagai negara tropis, kondisi agroekologi lahan di Indonesia sangat cocok untuk budidaya kelapa sawit. Indonesia merupakan penghasil sawit terbesar di dunia dan menjadi penyumbang devisa perdagangan terbesar. Perkembangan luas areal kelapa sawit di Indonesia pada kurun waktu 1980-2016 cenderung meningkat. Jika pada tahun 1980 luas areal kelapa sawit Indonesia sebesar 294,56 ribu hektar, maka pada tahun 2015 telah mencapai 11,30 juta hektar dan diprediksi menjadi 11,67 juta hektar pada tahun 2016. Pertumbuhan rata-rata selama periode tersebut sebesar 10,99\% per tahun. Sedangkan dari sisi produksi Crude Palm Oil (CPO), pada tahun 1980 produksi CPO Indonesia hanya sebesar 721,17 ribu ton dan naik menjadi 33,50 juta ton pada tahun 2016 atau tumbuh rata-rata sebesar $11,50 \%$ per tahun. Jika pada tahun 1981 volume ekspor kelapa sawit Indonesia hanya sebesar 201,25 ribu ton dengan nilai ekspor sebesar US\$ 108,85 juta, maka tahun 2015 meningkat menjadi 32,54 juta ton senilai US\$ 17,36 milyar (Pusdatin PPID, 2016).

Kelapa sawit sangat cocok baik pada kondisi lahan kering maupun basah, namun sebaran lokasi lahan perkebunan sawit ini sebagian besar berada di lahan mineral. Perkembangan terkini menunjukkan bahwa pengembangan perkebunan lahan sawit yang terhampar luas hanya tersisa di lahan basah, khususnya lahan gambut. Berdasarkan data dari Ditjen Perkebunan Kementrian Pertanian (2011), luas lahan gambut hingga tahun 2011 yang dimanfaatkan untuk pengembangan perkebunan sawit adalah seluas 1.539.579 Ha. Meskipun Indonesia mempunyai luas lahan gambut tropis terbesar di dunia, tapi tidak semua lahan gambut bisa dimanfaatkan untuk budidaya pertanian ataupun perkebunan, hal ini disesuaikan karakteristiknya dan ketebalan lahan gambut.

Fakta di lapangan menunjukkan bahwa sebagian lahan gambut yang dimanfaatkan untuk pertanian dan perkebunan banyak menjadi lahan terlantar tidak produktif, akan tetapi sebagian lainnya dengan pengelolaan yang baik ternyata mampu berproduksi dan telah berkontribusi meningkatkan kesejahteraan masyarakat di sekitarnya (Wahyunto et al., 2013). Perkembangan lahan gambut untuk pengembangan kebun sawit hingga tahun 2011 lebih dari 1.5 juta ha. Data Ditjen Perkebunan tahun 2011, Provinsi Riau dan Sumatera Utara tergolong wilayah pengembangan gambut untuk Sawit yang paling luas (Tabel 1).

Tabel 1. Perkembangan Luas Kebun Sawit di Tanah Mineral dan Lahan Gambut Hingga Tahun 2011.

Provinsi

\section{Luas Perkebunan Kelapa Sawit (Ha)}

\begin{tabular}{|c|c|c|c|c|c|c|}
\hline & & & & & & \multirow[t]{2}{*}{ (ton/ha) } \\
\hline & $\begin{array}{l}\text { Di tanah } \\
\text { mineral }\end{array}$ & $\%$ & $\begin{array}{l}\text { Di tanah } \\
\text { gambut }\end{array}$ & $\%$ & $\begin{array}{l}\text { Luas total } \\
\text { perkebunan }\end{array}$ & \\
\hline $\begin{array}{l}\text { N.A } \\
\text { Darusalam }\end{array}$ & 252.496 & 89,4 & 29.836 & 10,6 & 282.332 & 2,6 \\
\hline $\begin{array}{l}\text { Sumatera } \\
\text { Utara }\end{array}$ & 831.387 & 79,3 & 217.305 & 20,7 & 1.048 .692 & 3,7 \\
\hline $\begin{array}{l}\text { Sumatera } \\
\text { Barat }\end{array}$ & 290.755 & 85,6 & 48.920 & 1,4 & 339.675 & 2,6 \\
\hline Riau & 1.105 .098 & 58,4 & 788.491 & 41,6 & 1.893 .589 & 4,1 \\
\hline Kep. Riau & 8.130 & 100,0 & - & & 8.130 & 0,8 \\
\hline Jambi & 397.491 & 81,8 & 88.645 & 18,2 & 486.136 & 3,4 \\
\hline $\begin{array}{l}\text { Sumatera } \\
\text { Selatan }\end{array}$ & 643.938 & 90,9 & 64.118 & 9.1 & 708.056 & 3,8 \\
\hline Keb. Babel & 182.116 & 99,9 & 245 & 0,1 & 182.361 & 3,8 \\
\hline Bengkulu & 226.072 & 99,6 & 963 & 0,4 & 227.035 & 4 \\
\hline Lampung & 142.336 & 92,9 & 10.882 & 7,1 & 153.218 & 3,1 \\
\hline Sumatera & 4.079 .819 & 76,6 & 1.249 .405 & 23,4 & 5.329 .224 & $2,6-4,0$ \\
\hline Jawa Barat & 9.837 & 100,0 & 0 & 0,0 & 9.837 & 1,9 \\
\hline Banten & 14.894 & 100,0 & 0 & 0,0 & 14.894 & 2,8 \\
\hline Kalimantan & 1.796 .730 & 86,2 & 288.136 & 13,8 & 2.084 .866 & $2,4-3,7$ \\
\hline Sulawesi & 209.379 & 100,0 & 0 & 0,0 & 209.379 & $1,8-3,9$ \\
\hline $\begin{array}{l}\text { Papua \& } \\
\text { Papua Barat }\end{array}$ & 59.887 & 96,7 & 2.038 & 3,3 & 61.925 & $2,5-2,8$ \\
\hline Indonesia & 6.170 .546 & 80,0 & 1.539 .579 & 20,0 & 7.710 .125 & $1,9-4,1$ \\
\hline
\end{tabular}


Tren pengembangan sawit di lahan gambut, seiring dengan suksesnya pengembangan sawit yang bisa diatasi dari kendala-kendala agronomisnya. Kesuburan lahan dan sistem tata air yang sedikit banyak telah bisa diatasi kendalanya, menjadikan lahan gambut sebagai alternatif pengembangan ekstensifikasi pembangunan kebun sawit.

Pemanfaatan lahan gambut untuk budidaya tanaman perkebunan masih terkendala oleh berbagai faktor seperti ketebalan gambut, kemasaman yang tinggi, kesuburan yang rendah, adanya lapisan pirit, lapisan tanah dibawah gambut (substratum) yang berupa pasir kuarsa dan sistem tata air. Meskipun terdapat berbagai kendala, pembukaan lahan gambut untuk pengembangan kelapa sawit menunjukkan kecenderungan yang semakin meningkat. Peningkatan ini disebabkan karena berangsurangsur berbagai kendala sudah bisa diatasi atau dipahami oleh para praktisi perkebunan kelapa sawit. Namun juga masih ada para praktisi perkebunan sawit yang kurang memahami karakteristik lahan gambut, sehingga ancaman terhadap produktivitas lahan yang rendah dan tidak berkelanjutan. Kurangnya pemahaman ini masih menganggap pola pengelolaan lahan gambut untuk pengembangan perkebunan kelapa sawit sama saja seperti di tanah mineral atau rawa pasang surut. Beberapa perusahaan besar telah mengelola lahan gambut untuk perkebunan kelapa sawit, namun ketebalan gambut yang terlalu dalam dan tingkat kematangan gambut berupa gambut fibrik, maka produktivitasnya juga rendah seperti di daerah Pekan Tua, Kabupaten Indragiri Hilir, Riau. Produktivitas pada lahan gambut tebal dengan pengelolaan standar hanya akan menghasilkan produksi kurang dari 3 ton Tandan Buah Segar (TBS) per ha. Pola pengelolaan yang kurang baik selain menyangkut kesesuaian agroinput (penyuburan lahan) adalah managemen tata air yang tidak terkelola dengan baik seperti pengaturan tinggi muka air yang optimal. Namun apabila lahan gambut dikelola secara baik dan disesuaikan dengan standar kondisi kesuburan lahan gambut, maka produksinya masih tergolong tinggi. Pertanaman kelapa sawit pada lahan gambut mampu menghasilkan TBS 20,25-23,74 ton/ha/tahun (Barchia, 2006). Lebih spesifik lagi, menurut Wiratmoko et al. (2008), kelapa sawit yang ditanam di lahan gambut topogen dapat menghasilkan TBS 19,64-25,53 ton/ha/tahun. Sebagai pembanding, menurut Lubis \& Wahyono (2008), pengusahaan kelapa sawit pada lahan mineral dapat menghasilkan TBS rata-rata 22,26 ton/ha/tahun dengan puncak produksi sekitar 27,32 ton/ha/tahun.

Bagaimanapun, disatu sisi lahan gambut merupakan potensi besar sebagai lahan yang mempunyai nilai ekonomi untuk pengembangan produksi kelapa sawit, disisi lain lahan gambut merupakan lahan basah yang rentan (fragile) terhadap kondisi lingkungan yang apabila dibuka perlu memahami karakteristik gambut, baik aspek kesuburannya maupun sistem tata airnya. Sebagaimana diketahui juga sebagai ekosistem yang fragile, pemerintah telah mengeluarkan regulasi tentang pengelolaan lahan gambut baik sebagai kawasan konservasi maupun kawasan budidaya. Upaya ekspansi besar-besaran pengembangan lahan gambut untuk kawasan budidaya (pertanian dan perkebunan) ternyata memberi implikasi besar terhadap dampak lingkungan gambut terutama aspek konservasi sumberdaya hayati, emisi karbon, penambat air dan kebakaran lahan gambut. Untuk pengendalian pemanfaatan gambut ini pemerintah telah membuat regulasi Peraturan Pemerintah (PP) Nomor 71 Tahun 2014 tentang kebijakan perlindungan dan pengelolaan ekosistem gambut. Sehingga setiap pemanfaatan gambut harus mempertimbangkan aspek karakteristik gambut terutama ketebalan dan fungsi ekosistem lahan basah (biodiversitas dan hidrorologis). Pada makalah ini akan dipaparkan kajian tentang sistem pengelolaan tata air di lahan gambut untuk pengembangan perkebunan sawit dengan studi kasus pada perusahaan kelapa sawit di lahan gambut. Sehingga dari evaluasi ini dapat diketahui potret pengembangan sawit di lahan gambut baik yang seharusnya dilakukan oleh investor perkebunan kelapa sawit untuk menjaga sistem kelestarian produksi dan lingkungan.

\subsection{Tujuan}

Tujuan dari penelitian ini adalah :

1. Mengkaji pengelolaan tata air di area lahan gambut perkebunan kelapa sawit khususnya terkait dengan kondisi karakteristik gambut dan implikasinya terhadap produktivitas sawit.

2. Mengkaji pengelolaan tata air terkait kerentanannya terhadap overdrainage saluran yang implikasinya pada munculnya racun pirit (oksidasi) dan ancaman bahaya kebakaran lahan.

\section{METODOLOGI}

\subsection{Pengumpulan Data}

Data yang dikumpulkan meliputi data sekunder dan primer. Data sekunder diambil dari data statistik produksi perkebunan dan studi literatur. Selain itu juga peta-peta seperti peta land system, peta kerja perusahaan perkebunan sawit dan peta kanal-kanal reklamasi lahan kebun kelapa sawit. Untuk data primer dilakukan dengan survei lapangan yang dilakukan pada bulan Oktober tahun 2015. Pengukuran dan pengamatan lapangan di lokasi studi (Gambar 1) meliputi kondisi topologi berbagai saluran, muka 
air saluran dan muka air tanah (lahan) dan kinerja pertumbuhan tanaman sawit dan produksinya.

\subsection{Pengolahan Data}

Data yang telah dikumpulkan baik data primer dan data sekunder dilakukan analisis kuantitatif dan tabulatif dengan analisis keterkaitan antara parameter karakteristik biofisik lahan (muka air saluran, muka air tanah, kondisi biofisik lahan dan kondisi agronomis tanaman dan produksi).

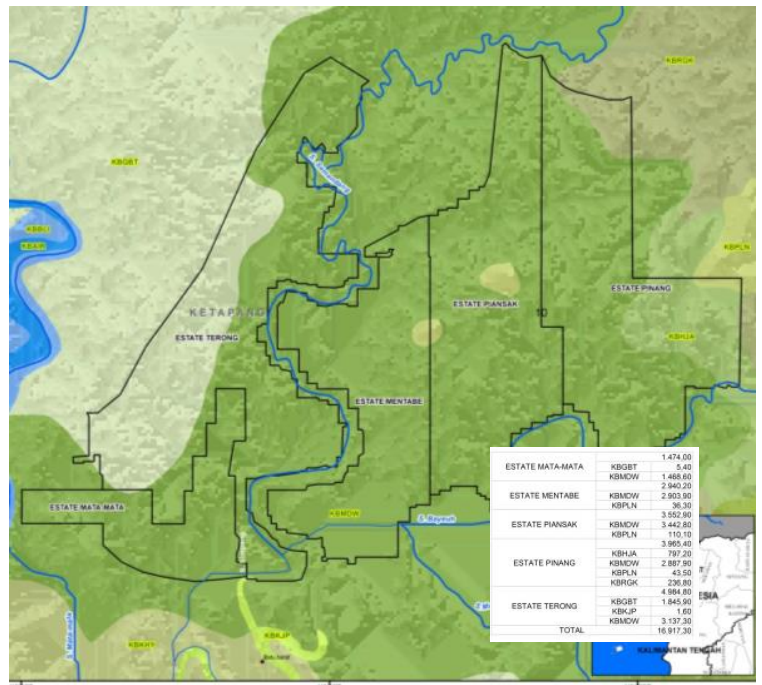

Gambar 1. Lokasi studi dan sistem lahan gambut di wilayah Perkebunan Kelapa Sawit PT JV Kabupaten Kayong Utara Kalimantan Barat.

\section{HASIL DAN PEMBAHASAN}

\subsection{Kondisi Lahan Gambut dan Karakteristiknya}

Gambut merupakan lahan basah dan merupakan ekosistem yang fragile. Lahan gambut merupakan suatu ekosistem lahan basah yang dibentuk oleh adanya penimbunan/akumulasi bahan organik di lantai hutan yang berasal dari reruntuhan vegetasi di atasnya dalam kurun waktu lama. Akumulasi ini terjadi karena lambatnya laju dekomposisi dibandingkan dengan laju penimbunan bahan organik di lantai hutan yang basah/tergenang tersebut (Najiyati et al., 2005). Ekosistem hutan rawa gambut ditandai dengan adanya kubah gambut di bagian tengah dan mendatar/rata di bagian pinggir serta digenangi air berwarna coklat kehitaman seperti teh atau kopi sehingga sering disebut ekosistem air hitam. Kubah gambut (peat dome) diawali oleh pembentukan gambut topogen di lapisan bawah lalu diikuti oleh pembentukan gambut ombrogen di atasnya. Dalam pembentukan gambut ombrogen, vegetasi bergantian tumbuh mulai dari pionir, sekunder, klimaks, mati dan tertimbun di situ, sehingga lama-kelamaan timbunan bahan organik gambut semakin tebal. Situasi ini mengarahkan keadaan lingkungan ekosistem gambut semakin ekstrim asam, miskin hara dan anaerob. Pada kubah gambut, pasokan hara semata-mata hanya datang dari air hujan, tidak ada lagi pasokan hara dari air tanah maupun sungai. Kondisi tersebut menyebabkan semakin sedikitnya jenis tumbuhan yang mampu beradaptasi dan tumbuh di atasnya (Wibisono et al, 2005).

Lahan gambut di lokasi studi yaitu di PT Jalin Vaneo Kabupaten Kayong Utara merupakan jenis lahan gambut dari sistem lahan gambut Mendawai (MDW) dan Gambut (GBT). GBT merupakan daerah rawa gambut dalam, biasanya merupakan kubah gambut, dengan slope kurang dari $2 \%$. Secara litologi, tipe batuan yang dominan adalah gambut dengan jenis tanahnya adalah Tropohemists dan Tropofibrists. Sedangkan MDW merupakan daerah rawa gambut dangkal, memiliki slope kurang dari $2 \%$. Secara litologi, tipe batuan yang dominan adalah gambut, dengan jenis tanahnya adalah Troposaprists, dan Tropohemists.

Berdasarkan sebarannya, sistem lahan yang ada di wilayah studi ini lebih dominan MDW. Sistem lahan MDW terdiri dari asosiasi tanah Troposaprist, Tropohemist dan Tropaquents. Jenis tanah gambut ini tentunya mempunyai karakteristik yang berbeda antara yang satu dengan yang lain. Perbedaan ini disamping karena sifat pelapukan material bahan organik tanah tersebut atau tingkat mineralisasi bahan organik, juga tingkat ketebalan gambut. Pada gambut yang telah termineralisasi, kandungan serat sudah sedikit serta mempunyai bobot yang lebih tinggi dibandingkan dengan yang belum termineralisasi. Terdapat tiga macam tingkat dekomposisi bahan organik tanah gambut yaitu fibrik, hemik dan saprik. Fibrik yaitu bahan gambut yang mempunyai tingkat dekomposisi rendah, pada umumnya memiliki bulk density kandungan serat $\geq 3 / 4$ volumenya, dan kadar air saat jenuh berkisar $850 \%$ hingga $3000 \%$ dari berat kering oven bahan, warnanya coklat kekuningan, coklat tua atau coklat kemerah-merahan. Hemik yaitu bahan gambut yang mempunyai tingkat dekomposisi sedang, bulk density antara 0,13$0,29 \mathrm{~g} / \mathrm{cm}^{3}$. Saprik yaitu bahan gambut yang mempunyai tingkat kematangan yang paling tinggi, bulk density $\geq 0,2 \mathrm{~g} / \mathrm{cm}^{3}$ (Andriesse, 1997; Wahyunto et al., 2004).

Karakteristik fisik gambut yang penting dalam pemanfaatannya untuk tanaman kelapa sawit meliputi kadar air, berat isi (bulk density atau $B D$ ), daya menahan beban, subsiden dan kering tidak balik. Kadar air tanah gambut berkisar antara 100-1.300\% dari berat keringnya (Mutalib et al., 1991). Kadar air yang tinggi menyebabkan BD menjadi rendah, gambut menjadi lembek dan daya menahan bebannya rendah (Nugroho et al., 1997). Hasil pengamatan di lapangan, tanah gambut di lokasi studi mempunyai ketebalan yang bervariasi dari berkisar $1.2 \mathrm{~m}$ hingga $7.5 \mathrm{~m}$. Tingkat ketebalan ini penting terkait 
pemanfaatannya untuk pengembangan budidaya Kelapa Sawit. Sebagaimana diketahui, gambut tergolong tanah marginal untuk tanaman kelapa sawit karena mempunyai drainase, sifat fisik dan kimia yang kurang baik. Sifat kimia yang kurang baik antara lain $\mathrm{pH}$ tanah yang sangat rendah sekitar 3,5-4.0, nisbah $\mathrm{C} / \mathrm{N}$ yang tinggi, perimbangan $\mathrm{K}, \mathrm{Ca}, \mathrm{Mg}$ dapat dipertukarkan rendah di banding KTK gambut yang tinggi, perimbangan $\mathrm{K}$, Ca dan Mg yang tidak baik serta ketersedian unsur mikro sangat rendah yang diikat oleh koloid organik dari tanah gambut. Berdasarkan zonasi pemanfaatan gambut untuk pengembangan tanaman keras (Kelapa Sawit), kesesuaian gambut untuk budidaya kelapa sawit yaitu pada kedalaman antara $1.5 \mathrm{~m}$ hingga $3 \mathrm{~m}$. Hal ini berarti kedalaman gambut yang lebih dangkal bisa direkomendasikan untuk tanaman pangan atau hortikultura, sedangkan untuk gambut dalam atau tebal tidak direkomendasikan untuk tanaman pangan.

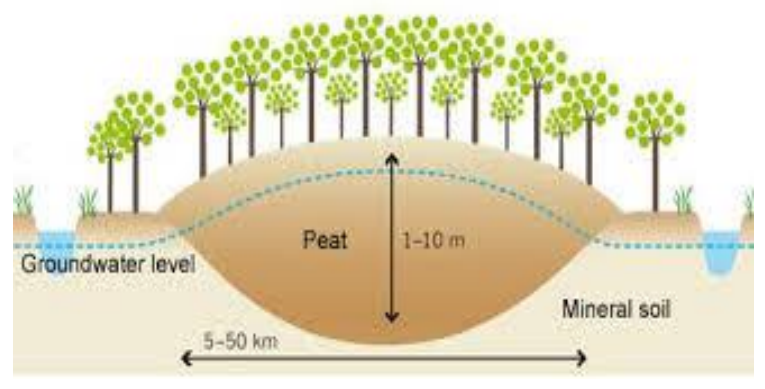

Gambar 2. Kubah (Dome) gambut (Jaenicke, 2010) .

Selain sifat-sifat fisik diatas, ketebalan gambut juga dapat mengindikasikan tingkat kesuburan lahan gambut. Gambut dangkal dengan ketebalan kurang dari $1 \mathrm{~m}$ jauh lebih baik/subur dibandingkan dengan gambut tebal apalagi gambut tebal yang berupa kubah (dome) (Gambar 2). Hasil penelitian oleh BPPT di Kabupaten Siak, gambut tebal/dalam bisa mempunyai ketebalan hingga 17m. Gambut pedalaman yang berupa dome tentunya sangat tidak cocok untuk pengembangan kebun sawit. Gambut pinggiran dari dome yang mempunyai ketebalan kurang dari $1 \mathrm{~m}$ seperti pada gambut pada sistem lahan MDW dan KHY relatif lebih cocok untuk pengembangan perkebunan kelapa sawit. KHY atau Kahayan merupakan daerah bantaran sungai, memiliki slope kurang dari $2 \%$ dan relief daerah antara 2 sampai 10 meter. Secara litologi, tipe batuan yang dominan adalah alluvium dengan estuarine-marine muda, alluvium dengan riverine muda, dan gambut. Sedangkan jenis tanahnya adalah Tropaquepts, Fluvaquents, dan Tropohemist. Di lokasi studi pada gambut dangkal pertumbuhan tanaman sawit relatif lebih baik dibandingkan dengan pada gambut pedalaman (lebih jauh dari pengaruh limpasan air sungai). Sistim tata air yang mengendalikan muka air saluran dilakukan dengan mengatur muka air disaluran utama (primer) hingga saluran yang paling kecil (kuarter) serta saluran cacing. Pola tata air di saluran untuk pengaturan kelembapan tanah di tingkatan lahan diilustrasikan pada Gambar 3. Indikasi pertumbuhan yang lebih baik ditunjukkan dengan pelepah daun lebih panjang dan lebar, warna lebih hijau dan batang pohon juga nampak lebih besar. Pertumbuhan dan produktivitas tanaman di Estate Terong lebih bagus dibandingkan dengan tanaman di blok Estate Piansak dimana Estate ini berada pada sistem lahan GBT yang mempunyai kedalaman gambut hingga lebih dari $2 \mathrm{~m}$.

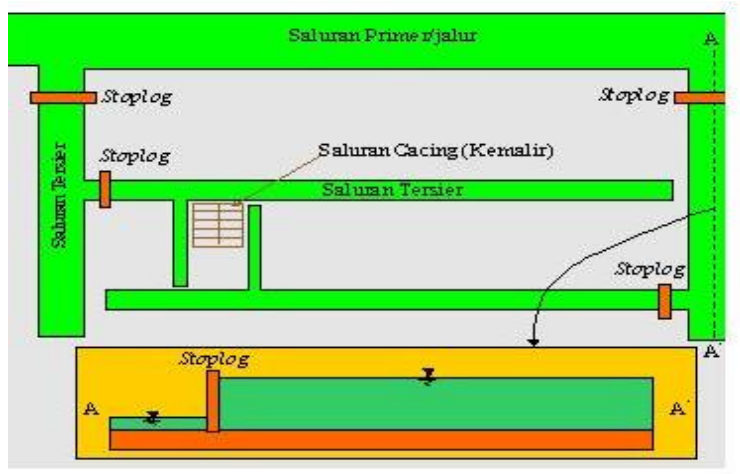

Gambar 3. Sistem Tata Air di Lahan Gambut (Haerani \& Nursyamsi, 2012)

\subsection{Sistem Pengelolaan Tata Air}

Pengelolaan air di lahan gambut bertujuan untuk mengatur pemanfaatan sumber daya air secara optimal sehingga didapatkan hasil/produktivitas lahan yang maksimal, serta sekaligus mempertahankan kelestarian sumber daya lahan tersebut. Salah satu teknik pengelolaan air di lahan gambut dapat dilakukan dengan membuat parit/saluran, dengan tujuan:

- Mengendalikan keberadaan air tanah di lahan gambut sesuai dengan kebutuhan tanaman yang akan dibudidayakan. Artinya: gambut tidak menjadi kering di musim kemarau, tapi juga tidak tergenang di musim hujan. Hal demikian dapat dicapai dengan membuat pintu air yang dapat mengatur tinggi muka air tanah gambut sekaligus menahan air yang keluar dari lahan.

- Mencuci asam-asam organik dan anorganik serta senyawa lainnya yang bersifat racun terhadap tanaman dan memasukan (suplai) air segar untuk memberikan oksigen.

Salah satu faktor kunci keberhasilan pengembangan pertanian di lahan gambut, selain meningkatkan kesuburannya adalah mengendalikan tinggi muka air di dalamnya sehingga gambut tetap basah tapi tidak tergenang dimusim hujan dan tidak kering di musim kemarau. Pengendalian muka air pada budidaya sawit di lahan gambut dipertahankan pada kisaran muka air tanah sekitar 60-80 cm dari permukaan 
tanah. Pengaturan tinggi muka air yang tepat juga dimaksudkan agar proses pencucian bahan beracun berjalan dengan lancar sehingga tercipta media tumbuh yang baik bagi tanaman.

Pengelolaan tata air pada perkebunan kelapa sawit, utamanya dimaksudkan untuk mengkondisikan lahan pertanaman jangan sampai selalu sering tergenang ataupun jangan terlalu kering. Artinya pengelolaan tata air utamanya adalah mengkondisikan lahan dalam kondisi tanah pada kapasitas lapang. Kondisi pada kapasitas lapang, tanah bisa mendukung ketersediaan air bagi pertumbuhan tanaman sawit.

Hasil pengamatan di lapangan menunjukkan bahwa saluran dalam kondisi overdrainage. Paradigma pencucian saluran kurang dipahami secara benar. Pencucian saluran sebenarnya dimaksudkan untuk mengkondisikan saluran tetap mengalir akan tetapi dipertahankan pada kedalaman tertentu, sehingga saluran tetap berisi air dan selalu mengalir. Pengaturan sistem tata air tetap mempertimbangkan kondisi topografi areal kebun, sehingga pergerakan air didesain sedemikian selalu mengalir, dan dipertahankan pada kedalaman sesuai dengan hasil pemetaan kedalaman lapisan pirit. Banyak yang harus dibenahi secara total manajemen tata air ini, pembuatan stoplog (bendung kecil/sederhana), perlu segera dibangun untuk mencegah saluran dalam kondisi kering.

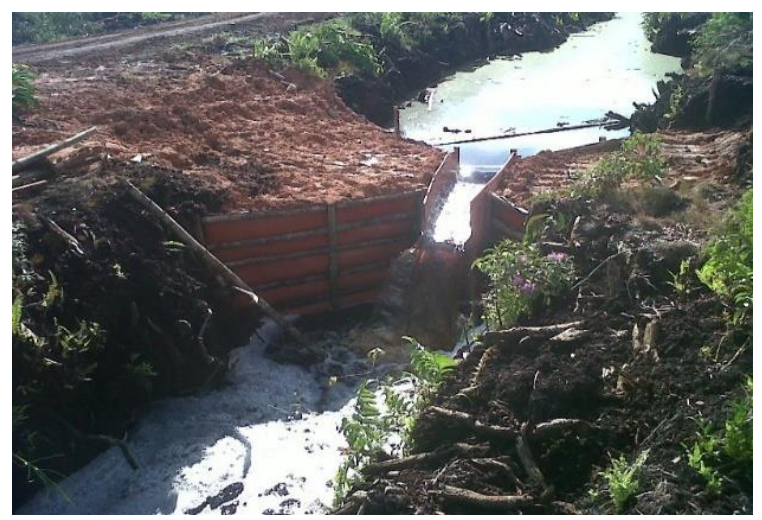

Gambar 4. Stop Log/Stop Block untuk pengendalian muka air saluran dan overdrainage.

Pembangunan stoplog seperti terlihat pada Gambar 4 tentunya disesuaikan dengan tingkat kemiringan dari saluran, artinya apabila stoplog dibangun terlalu jauh dapat menyebabkan saluran sebelah hulunya akan kering. Kemiringan saluran yang relatif datar akan membutuhkan stoplog yang jarak antar stoplognya bisa jauh, sedangkan apabila kemiringan saluran terlalu ekstrim, maka jarak antar stoplog akan lebih dekat. Drainase lahan rawa pasang surut termasuk lahan gambut bisa menyebabkan senyawa pirit yang terkandung di dalam tanah menjadi teroksidasi (Zhang \& Luo, 2002). Proses oksidasi senyawa pirit menghasilkan asam sulfat yang berakibat terjadi proses pemasaman tanah yang hebat. Kendala utama dalam pengembangan lahan rawa pasang surut untuk pengembangan kawasan budidaya persawahan atau perkebunan (sawit) adalah reaksi tanah yang sangat masam dan sumber utama pemasaman tanah adalah oksidasi senyawa pirit (Priatmadi, 2008).

\subsection{Overdrainage}

Pengamatan kondisi muka air saluran merupakan parameter yang diamati dalam penelitian ini. Hasil pengukuran dari pemboran tanah gambut di beberapa titik Blok, muka air dilahan bervariasi antara $39 \mathrm{~cm}$ hingga $130 \mathrm{~cm}$ (Gambar 5).

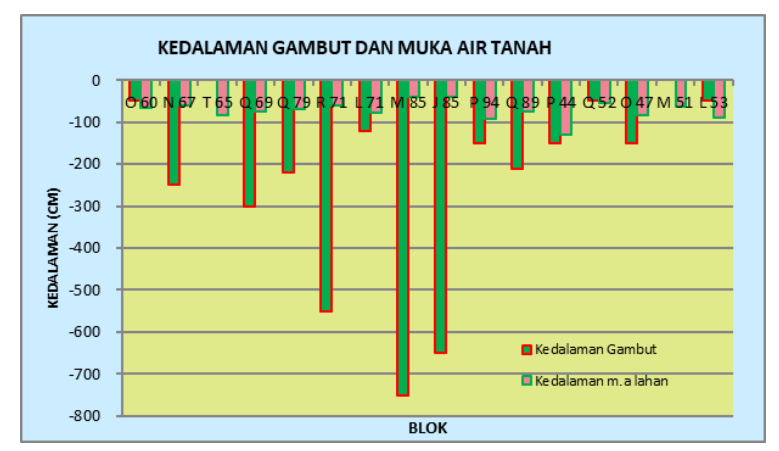

Gambar 5. Kedalaman gambut dan muka air tanah pada beberapa Blok di wilayah kebun Sawit PT. Jalin Vaneo, Kabupaten Kayong Utara

Kisaran ideal sebaran kedalaman muka air pada kedalaman $40 \mathrm{~cm}$ hingga $60 \mathrm{~cm}$. Hasil pengamatan lapangan menunjukkan saluran tata air banyak dalam kondisi overdrainage. Saluran dalam kondisi overdrainage adalah saluran sekunder dan saluran blok pertanaman seperti di Blok L53, Q47, P94 dan Q69. Kegiatan pembersihan saluran dari gulma dan pendalaman saluran dari dampak sedimentasi menyebabkan overdrainage. Overdrainage ini menyebabkan lapisan pirit teroksidasi dan berakibat memunculkan jarosit. Sebagaimana disebutkan dalam subbab sebelumnya, paradigama pencucian saluran dimaknai sebagai kegiatan untuk mendrainase air saluran hingga habis, sehingga menyebabkan banyak saluran dalam kondisi kosong air atau overdrainage. Hal yang mendasar kurang dipahami adalah sifat-sifat tanah yang ada di area lahan pertanaman. Tanah yang dianggap rawa bukan berarti direklamasi untuk diatur secara habis air di lahannya, akan tetapi seharusnya dikelola mengikuti kaidahkaidah sifat-sifat tanah dan ketersediaan air bagi tanaman sepanjang musim. Artinya saluran harus dikondisikan ketersediaan airnya hingga pada muka air tertentu (kisaran $50 \mathrm{~cm}$ ). Overdrainage pada tanah Sulfaquents, Tropohemist dan Troposaprist yang mengandung lapisan pirit berimplikasi pada munculnya lapisan pirit yang teroksidasi serta kekeringan di lahan pada saat 
musim kemarau yang bisa menjadi ancaman bagi kelangsungan pertumbuhan dan produktivitas tanaman serta ancaman kebakaran lahan gambut. Overdrainage yang terus menerus terjadi, mengakibatkan percepatan mineralisasi gambut dan terbukti mengubah lahan gambut menjadi sumber karbon dioksida dan methane yang berakibat terhadap kontribusi pemanasan global (Vermaata et al., 2016).

Pengaturan muka air di saluran dengan stop log/stop block mengkondisikan air di lahan pertanaman menjaga tanah dalam kondisi kapasitas lapang yang berkesinambungan. Nampak pada blok-blok pertanaman yang muka air tanahnya terjaga dengan baik, kondisi kinerja agronomis tanaman sawit juga baik seperti warna daun lebih hijau, lebar pelepah dan bentuk batang tanaman juga relatif lebih sempurna dibandingkan pada blok pertanamanan yang overdrainage meskipun kedalaman gambutnya lebih dangkal.

\subsection{Lapisan Pirit}

Hasil pengamatan di lapangan, kenyataannya tanah-tanah di lokasi studi sebagian mengandung lapisan pirit. Kedalaman lapisan pirit yang terdeteksi antara $40 \mathrm{~cm}$ hingga $60 \mathrm{~cm}$. Beberapa lokasi yang terindikasi mempunyai kedalaman lapisan pirit yang dangkal perlu kehati-hatian dalam mengelola muka air saluran. Lapisan pirit dengan kedalaman $40 \mathrm{~cm}$ ini tergolong dangkal.

Pirit sebagai senyawa $\mathrm{FeS}_{2}$ akan stabil dalam kondisi an aerob pada tanah tanah berawa (sulfat masam dan gambut). Overdrainage pada saluran dan melampaui batas lapisan kedalaman pirit akan berakibat oksidasi pirit. Pirit yang teroksidasi akan menghasilkan racun Jarosit dan menampakan warna karat atau kuning kemerahan pada genangan air atau warna karat kekuningan pada singkapan tanah yang mengandung lapisan pirit. Pirit yang teroksidasi akan meningkatkan kemasaman air hingga mencapai pH 3 bahkan bisa mempunyai $\mathrm{pH} 2$ dan mengakibatkan kelaruran $\mathrm{Fe}$ dan $\mathrm{Al}$ pada air meningkat. Sebagaimana dijelaskan berikut bila pirit teroksidasi, unsur besi yang terkandung di dalam pirit berubah bentuk dan bersifat racun bagi tanaman. Bukan hanya itu, proses oksidasi pirit juga menyebabkan tanah menjadi lebih masam karena ion hidrogen $(\mathrm{H})$ yang merupakan penentu tingkat kemasaman tanah banyak dilepaskan selama proses oksidasi tersebut. Selanjutnya, tanah yang masam menyebabkan ion aluminium (Al) yang ada di dalam tanah terlepas dan bersifat racun bagi tanaman.

Kondisi di dalam tanah yang jenuh akan ion besi dan aluminium yang terlepas akibat oksidasi pirit, ibarat magnet yang selalu mencari logam di dekatnya dan segera menempelnya, ion besi dan aluminium yang jenuh di dalam tanah akan menarik dan menempel ion fosfat $\left(\mathrm{PO}_{4}\right)$ yang ada di dalam tanah sehingga tidak dapat diserap oleh akar tanaman. Akibatnya, akan terjadi kekurangan unsur fosfor $(P)$ dalam tanah, padahal unsur fosfor diperlukan tanaman untuk pembentukan bunga dan buah.

Penelitian tentang penanganan pirit telah banyak dilakukan dalam rangka kegiatan budidaya pertanian dan perkebunan untuk keberlanjutan produksi. Hasil penelitian Priatmadi \& Haris, (2009) menyebutkan bahwa laju pemasaman tanah dari bahan sulfidik lebih cepat dibandingkan dengan lapisan tanah atas ketika tanah dan bahan sulfidik teroksidasi lebih lanjut. Pada kondisi tanah dengan kandungan air tinggi, pemberian bahan amelioran (silika, fosfat dan kapur) efektif meningkatkan $\mathrm{pH}$ pada lapisan tanah atas. Pada kondisi tanah dan bahan sulfidik teroksidasi lanjut atau kandungan air rendah, pemberian amelioran (silika, fosfat dan kapur) dapat menghambat pemasaman tanah atas dan bahan sulfidik tetapi dapat meningkatkan kelarutan besi pada tanah lapisan atas dan bahan sulfidik. Amelioran diharapkan akan menyelimuti pirit sehingga senyawa pirit yang bereaksi tehadap oksigen, reaksi oksidasi dapat dihambat. Dengan terhambatnya reaksi oksidasi pirit, maka reaksi pemasaman tanah juga akan terhambat. Shamshuddin \& Sarwani (2002) menyebutkan bahwa bahan-bahan alami dapat digunakan untuk menghambat reaksi pemasaman pirit.

\subsection{Kebakaran Lahan}

Kendala lain pada tanah gambut selain munculnya racun akibat oksidasi pirit oleh karena overdrainage adalah kebakaran gambut. Apabila gambut mengalami pengeringan yang berlebihan, maka koloid gambut menjadi rusak dan kering sehingga risiko bahaya kebakaran lahan sangat tinggi. Terjadi gejala kering tak balik (irreversible drying) dan gambut berubah sifat seperti arang sehingga tidak mampu lagi menyerap hara dan menahan air (Subagyo et al, 1996). Lebih lanjut dijelaskan juga bahwa gambut akan kehilangan air tersedia setelah 4-5 minggu pengeringan dan ini mengakibatkan gambut mudah terbakar. Kenyataan di lapangan di beberapa blok kelapa sawit yang overdrainage juga terjadi kebakaran lahan.

Kebakaran hutan dan lahan gambut selama musim kering dapat disebabkan atau dipicu oleh kejadian alamiah dan juga kegiatan atau kecerobohan manusia. Kejadian alamiah seperti terbakarnya ranting dan daun kering secara sertamerta (spontan) akibat panas yang ditimbulkan oleh batu dan benda lainnya yang dapat menyimpan dan menghantar panas, dan pelepasan gas metana $(\mathrm{CH} 4)$ telah diketahui dapat memicu terjadinya kebakaran (Abdullah et al., 2002). Meskipun demikian, pemicu utama terjadinya kebakaran adalah adanya kegiatan dan atau kecerobohan manusia, yang 90-95\% merupakan faktor pemicu kejadian kebakaran. 
Faktor manusia yang dapat memicu terjadinya kebakaran meliputi pembukaan lahan dalam rangka pengembangan pertanian berskala besar dan persiapan lahan untuk budidaya tanaman oleh petani. Pembukaan dan persiapan lahan oleh petani dengan cara membakar merupakan cara yang murah dan cepat terutama bagi tanah yang berkesuburan rendah. Banyak penelitian telah menunjukkan bahwa cara ini cukup membantu memperbaiki kesuburan tanah dengan meningkatkan kandungan unsur hara dan mengurangi kemasaman (Diemont et al., 2002). Hanya saja jika tidak terkendali, kegiatan ini dapat memicu terjadinya kebakaran lahan secara luas.

\subsection{Produksi Kelapa Sawit}

Budidaya kelapa sawit di lahan gambut akan berhadapan dengan faktor pembatas utama, yaitu masalah drainase. Pada kondisi alami, gambut mengandung air yang berlebihan dengan kapasitas memegang air (water holding capactity) 20-30 kali dari beratnya, sehingga menimbulkan kondisi aerasi yang buruk. Keberhasilan penanaman kelapa sawit di lahan gambut dimulai dengan pembangunan sistem pengelolaan air (water management) yang baik. Pengelolaan air yang efektif adalah kunci untuk mendapatkan pertumbuhan dan produktivitas yang optimal sesuai potensi tanaman. Dengan mempertahankan ketinggian air 40-60 cm dari permukaan tanah diharapkan dapat memperbaiki zona perakaran sehingga penyerapan unsur hara menjadi lebih optimal.

Pengaturan muka air ini sangat penting juga terkait dengan potensi adanya racun pirit. Produktivitas tanaman kelapa sawit pada kedalaman pirit dangkal lebih rendah dari pada produktivitas pada kedalaman pirit yang lebih dalam. Pemetaan kedalaman lapisan pirit tentunya sangat penting terkait dengan potensi munculnya oksidasi pirit. Dengan indikasi lapisan pirit lebih dalam, sehingga peluang terjadianya overdrainage yang memungkinkan terjadinya potensi munculnya oksidasi pirit akan cenderung lebih tidak mungkin terjadi. Sehingga juga akan menghindari kendala hara akan terserap lebih baik dibandingkan apabila lapisan pirit lebih dangkal. Hasil penelitian menunujukkan pada jenis tanah Sulfic Endoaquepts dengan kedalaman pirit $100 \mathrm{~cm}$ menghasilkan produksi 3.8 hingga 4.5 ton TBS/ha/th. Sedangkan pada jenis tanah Typic Sulfaquepts dengan kedalam pirit $50 \mathrm{~cm}$ menghasilkan produksi 2.5 hingga 3.2 ton TBS/ha/th. Begitu juga berdasarkan jumlah tandan, pada kedalaman pirit lebih dalam yaitu $100 \mathrm{~cm}$, jumlah tandan mencapai 6-9 per pohon, sedangkan pada kedalaman pirit $50 \mathrm{~cm}$ jumlah tandannya mencapai 5-6 buah per pohon. Sehingga kedalaman pirit pada tanah tanah rawa, sufat masam ataupun gambut, akan mempengaruhi tingkat produktivitasnya. Kedalaman pirit lebih dangkal akan lebih rawan tersingkap dan teroksidasi apabila pola sistem tata air saluran kurang mengikuti kaidah dan pemahaman tentang perilaku racun pirit (oksidasi). Sebagaimana telah dijelaskan diatas, kelarutan $\mathrm{Al}$ dan $\mathrm{Fe}$ akan meningkat seiring dengan oksidasi pirit dan peningkatan kemasaman tanah. Kelarutan Al dan Fe yang semakin meningkat ini menyebabkan ketersediaan phospat atau serapan hara untuk pertumbuhan tanaman menjadi semakin menurun. Secara tidak langsung tentunya juga akan mengakibatkan pertumbuhan dan produksi tanaman tidak bisa optimal. Hasil penelitian Veloo et al (2015), menunjukkan bahwa stratum dasar dari gambut berupa pasir memberikan hasil produksi sawit yang lebih tinggi dibandingkan liat marin. Sementara itu kedalaman gambut tidak signifikan terhadap produksi hasil kecuali terhadap sifat gambut yang masih mengandung kayu tinggi. Gambut yang masih mengandung kayu tinggi (belum terlapuk) berpengaruh terhadap hasil produksi yang kurang baik dibandingkan dengan gambut yang telah termineralisasi. Begitu juga terhadap tingkat kematangan gambut, hasil penelitian menunjukkan bahwa jenis gambut memiliki pengaruh yang signifikan terhadap produksi kelapa sawit berkisar antara 9,47 - 22.92 ton/ha. Gambut yang lebih matang memiliki pengaruh paling signifikan pada hasil. Gambut Saprik menunjukkan berbagai hasil antara 19.48 - 22.92 ton/ha dibandingkan dengan gambut Hemic yang berkisar antara 9.47 - 13.37 ton/ha.

\section{KESIMPULAN}

- Pengelolaan muka air di saluran reklamasi sangat mempengaruhi tingkat keberhasilan produksi tanaman sawit pada sistem budidaya tanaman sawit di lahan gambut.

- Pengelolaan muka air di saluran dalam rangka untuk pengendalian overdrainage dan oksidasi pirit, juga sekaligus untuk menghindari potensi ancaman bahaya kebakaran lahan gambut.

- Produktivitas sawit pada lahan gambut dengan kedalam pirit $100 \mathrm{~cm}$ dengan muka air lebih dari lapisan pirit menghasilkan produksi sawit 3.8 - 4.5 ton TBS/ha/th. Produktivitas sawit pada kedalaman pirit $50 \mathrm{~cm}$, akan tetapi muka air tanah lebih dari $50 \mathrm{~cm}$, menghasilkan produksi sawit $2.5-3.2$ ton TBS/ha/th.

- Pengelolaan tata air dengan mengendalikan muka air saluran yang optimal untuk pembasahan lahan dan untuk mencapai produktivitas tanaman yang tinggi yaitu antara 40-60 cm.

- Blocking saluran dengan stoplog/stop block merupakan bentuk pengaturan tata air untuk menghindari overdrainage.

- Oksidasi pirit menyebabkan peningkatan kelarutan Al dan Fe sehingga menyebabkan 
peningkatan kemasaman tanah serta menyebabkan terganggunya serapan hara pada pertumbuhan kelapa sawit.

- Gambut lebih matang (termineralisasi) akan memberikan hasil produksi yang lebih baik dibandingkan dengan gambut yang belum terdekomposisi secara sempurna (gambut dalam/gambut fibris).

\section{DAFTAR PUSTAKA}

Abdullah, M.J., Ibrahim, M.R., Abdul Rahim, A.R. (2002). The Incidence of Forest Fire in Peninsular Malaysia: History, Root Causes, Prevention and Control. Proceeding of Workshop on Prevention and Control of Fire in Peatlands. Kuala Lumpur, 19-21 March 2002.

Andriesse, J.P. (1997). The Reclamation of Peatswamps and Peat in Indonesia. CWS Monograph, No. 1, Widiatmaka, Editor, Center for Wetland Studies, IPB, Bogor APHA.

Barchia, M.F. (2006). Gambut Agroekosistem dan Transformasi Karbon. UGM Press, Yogyakarta.

Diemont, W.H., Hillegers, P.J.M., Joosten, H., Kramer, K., Ritzema, H.P., Rieley, J., Wosten, H. (2002). Fire and Peat Forests, What are the Solutions?. Proceeding of Workshop on Prevention and Control of Fire in Peatlands. Kuala Lumpur, 19-21 March 2002.

Ditjen Perkebunan. (2011). Kebijakan Pengembangan Kelapa Sawit Berkelanjutan. Makalah disampaikan pada Seminar Implementasi RSPO di Indonesia. Jakarta, 10 Februari 2011.

Haerani, A., Nursyamsi, D. (2012). Pengelolaan Air: Kunci Keberhasilan Pertanian Rawa. Balittra. Banjarbaru.

Indonesian Climate Change Trust Fund (ICCTF). (2012). Sustainable Management of Degraded Peatland to mitigate GHG Emissionand Optimzed Crop production. Laporan kerjasama Penelitian ICCTF Bapennas - BBSDLP. Bogor.

Jaenicke, J. (2010). 3D Modelling and Monitoring of Indonesian Peatlands Aiming at Global Climate Change Mitigation. Dissertation., LMU München: Faculty of Biology.

Lubis., Wahyono, T. (2008). Keragaan Konflik Pengusahaan Lahan pada Perkebunan Kelapa Sawit di Sumatera. Jurnal Penelitian Kelapa Sawit 16(1), 47-59.

Mutalib, A.A., Lim, J.S., Wong, M.H., Koonvai, L. (1991). Characterization, Distribution and Utilization of Peat in Malaysia, Tropical Peat. Proceedings of the International Symposium on Tropical Peatland. Kuching, Serawak, Malaysia, pp 7-16.
Najiyati, S., Muslihat, L., Suryadiputra, I.N.N. (2005). Panduan Pengelolaan Lahan Gambut untuk Pertanian Berkelanjutan. Proyek Climate Change, Forests and Peatlands in Indonesia. Wetlands International - Indonesia Programme dan Wildlife Habitat Canada. Bogor. Indonesia.

Nugroho, K., Gianinazzi ,G., Widjaja Adhi, I.P.G. (1997). Soil Hidraulic Properties of Indonesian Peat. In: Rieley and Page (Eds.). pp. 147-156. Biodiversity and Sustainability of Tropical Peat and Peatland. Samara Publishing Ltd. Cardigan. UK.

Priatmadi, B.J. (2008). Pengaruh Pencucian Tanah Sulfat Masam Terhadap Sifat Kimia Tanah. J. Agroscientiae, 14, 88-95.

Priatmadi B.J., Haris, A. (2009). Reaksi Pemasaman Senyawa Pirit pada Tanah Rawa Pasang Surut. Jurnal Tanah Tropika, 14(1), 19-24.

Pusdatin PPID. (2016). Outlook Kelapa Sawit. Pusat Data dan Sistem Informasi Pertanian Sekretariat Jenderal - Kementerian Pertanian.

Shamshuddin, J., Sarwani, M. (2002). Pyrite in Acid Sulfate Soils: Transformation and Inhibition of Its Oxidation by Application of Natural Materials. 17th WCCS 14-21 August 2002, Thailand. Paper No. 97: 1-5.

Subagyo., Marsoedi., Karama, S. (1996). Prospek Pengembangan Lahan Gambut untuk Pertanian dalam Seminar Pengembangan Teknologi Berwawasan Lingkungan untuk Pertanian pada Lahan Gambut, 26 September 1996. Bogor.

Veloo, R,. van Ranst, E., Selliah, P. (2015). Peat Characteristics and Its Impact on Oil Palm Yield. NJAS - Wageningen Journal of Life Sciences, 72-73, 33-40. doi: 10.1016/j.njas.2014.11.001

Vermaata,J.E., Harmsen, J., Hellmann, F.A., van der Geest, H.G., de Klein, J.J.M., Kosten, S., Smolders, A.J.P., Verhoeven, J.T.A., Mes, R.G., Oubeter, M. (2016). Annual Sulfate Budgets for Dutch Lowland Peat Polders: The Soil is a Major Sulfate Source Through Peat and Pyrite Oxidation. Journal of Hydrology, 533, 515-522. doi: 10.1016/j.jhydrol.2015.12.038

Wibisono, I.T.C., Siboro, L., Suryadiputra, I.N.N. (2005). Panduan Rehabilitasi dan Teknik Silvikultur di Lahan Gambut. Proyek Climate Change, Forests and Peatlands in Indonesia. Wetlands International Indonesia Programme dan Wildlife Habitat Canada. Bogor. Indonesia.

Wahyunto., Sofyan, R., Suparto, Subagyo, H. (2004). Sebaran dan Kandungan Karbon Lahan Gambut di Sumatera dan Kalimantan. Wetland International Indonesia Programme. 
Wahyunto, Dariah, A., Pitono, D., Sarwani, M. (2013). Prospek Pemanfaatan Lahan Gambut untuk Perkebunan Kelapa Sawit di Indonesia. Perspektif, 12(1), 11-22.

Wiratmoko, D., Winarna, Rahutomo, S., Santoso, H. (2008). Karakteristik Gambut Topogen Dan Ombrogen di Kabupaten Labuhan Batu Sumatera Utara untuk Budidaya
Tanaman Kelapa Sawit. Jurnal Penelitian Kelapa Sawit, 16(3), 119-126.

Zhang, J., Luo, S. (2002). A Case Study on the Relationship Between Sulfur Forms and Acidity in Acid Sulphate Soils (ASS). 17 $7^{\text {th }}$ WCCS 14-21 August 2002, Thailand. Paper No. 1048: 1-5. 